\title{
Spinal block levels and cardiovascular changes during post-Cesarean transport
}

Edith Bandi MD, Sally Weeks MBBS FRCA, Franco Carli MD MPHIL FRCA

Purpose: Transport after surgery under spinal anesthesia is associated with cardiovascular changes. The extensively vasodilated patient may be unable to compensate for postural blood flow redistribution. This observational study investigated pre- and post-surgery sensory levels as well as hemodynamic changes during the postoperative transfer period.

Methods: One hundred ninety nine women, ASA I and 2, undergoing Cesarean section under spinal anesthesia were studied at the end of surgery. Hyperbaric bupivacaine $12-15 \mathrm{mg}$ and morphine $0.25 \mathrm{mg}$ were the agents used. Patients in group $A(n=111)$ were transferred to the Recovery Room on a stretcher with the upper body flexed $30^{\circ}$ head up: patients in group $B(n=88)$ remained supine during transport.

Results: At the end of Cesarean section $95 \%$ of patients had upper sensory levels of $T_{4}$ and higher. In $17.5 \%$ the block ascended 2-7 dermatomes compared with the pre-operative level. The incidence of hypotension on arrival in Recovery Room was similar in both groups (group A 10\% and group B 9\%).

Conclusion: These results draw attention to the persistence of extensive sympathetic block at the end of Cesarean section. Transport to the Recovery Room was associated with the development of considerable hypotension in $10 \%$ of patients and this was unaffected by position. We recommend recording the level of sensory block at the end of surgery and increased monitoring during transport to the Recovery Room.

Objectif : Le transport des malades après une opération sous rachianesthésie s'accompagne de modifications cardiovasculaires. Une importante vasodilatation ne permet pas de compensation pour la redistribution du débit sanguin postural. La présente étude voulait observer les niveaux sensitifs préopératoire et postopératoire ainsi que les changements hémodynamiques survenus pendant le transfert postopératoire.

Méthode : II s'est agi de l'observation en fin d'opération de 199 femmes, ASA I et II, ayant subi une césarienne sous rachianesthésie. Les anesthésiques ont été de 12 à $15 \mathrm{mg}$ de bupivacaine hyperbare et $0,25 \mathrm{mg}$ de morphine. Les patientes du groupe $A(n=111)$ ont été transportées à la salle de réveil sur une civière, le tronc en flexion de $30^{\circ}$; les autres patientes $(n=88)$ sont demeurées en décubitus dorsal pendant le transfert.

Résultats : À la fin de la césarienne, les niveaux sensitifs supérieurs se situaient à $T_{4}$ chez $95 \%$ des patientes. Chez $17,5 \%$, le blocage neuromusculaire s'est étendu de 2 à 7 dermatomes en comparaison avec le niveau préopératoire. L'incidence d'hypotension à l'arrivée à la salle de réveil a été similaire dans les deux groupes (groupe A, $10 \%$; groupe B, $9 \%$ ).

Conclusion : Ces résultats devraient attirer notre attention sur la persistance de blocage sympathique étendu à la fin d'une césarienne. Le transfert vers la salle de réveil a été associé au développement d'une importante hypotension chez $10 \%$ des patientes et ce, peu importe la position. Nous recommandons de noter le niveau de blocage sensitif à la fin de l'opération et d'accroître la surveillance pendant le transfert à la salle de réveil.

From the Departments of Anesthesia, Royal Victoria Hospital and McGill University, Montreal, Quebec, Canada.

Address correspondence to: Dr. Sally Weeks, Department of Anesthesia, Royal Victoria Hospital, 487 Pine Avenue West, Suite S5.05, Montreal, Quebec H3A IAl Canada. Phone: 514-842-1231, local 4880; Fax: 514-843-1723; E-mail: misw@musica.mcgill.ca Accepted for publication May 16,1999 
$\mathrm{T}$

HE period of transfer between Operating Room and Recovery Room after Cesarean section under spinal anesthesia has not been formally studied. Extensive sympathetic block, which may extend to the cardioaccelerator nerves, may lead to cardiovascular instability, especially during sudden postural changes.

A report from this institution described a cardiac arrest on arrival in the Recovery Room after Cesarean section under spinal anesthesia. ${ }^{1}$ In the subsequent correspondence, one of the unanswered questions was the height of the spinal block at the end of surgery. ${ }^{2}$ Therefore, we decided to record prospectively the levels of spinal block before and after completion of Cesarean Section. The cardiovascular changes associated with transport to Recovery Room were also studied.

\section{Methods}

This sequential study was approved by the Institutional Review Board. Patients gave written consent for data from their records to be used after arrival in Recovery Room. In this hospital, patients after spinal anesthesia for Cesarean section are routinely transported to the Recovery Room in the $30^{\circ}$ head up position. The first group of patients studied were transported in this manner (Group $A, n=111$ ). The second group was then studied and remained supine during transport (Group $B, n=88$ ). In an attempt to obtain an overview of the transport period, both elective and emergency patients were included and some patients were in labour. Patients were excluded from the study if they had preeclampsia and/or cardiovascular instability at the end of surgery prior to transport.

Clinical routine procedures were not modified for study purposes. Patients received subarachnoid 12-15 $\mathrm{mg}$ hyperbaric bupivacaine $0.75 \%$ with $0.2-0.25 \mathrm{mg}$ morphine $(0.4-0.5 \mathrm{ml})$ using a $27 \mathrm{G}$ Quincke or $25 \mathrm{G}$ Whitacre needle, according to the preference.of the anesthesiologist. The injection was made in the sitting position at $\mathrm{L}_{2-3}$ or $\mathrm{L}_{3-4}$, and the patients were then placed supine with left uterine displacement. Sensory block was determined using loss of temperature sensation to ice in the mid-axillary line, moving in a cranial direction. Testing was started after completion of the block but was stopped when a sensory level of $T_{6}$ or higher was achieved when preparation for surgery was allowed to proceed. At the end of surgery, prior to transfer from the OR table, the block was tested again in the same manner.

The following were recorded: age, height, the time of subarachnoid injection, height of cephalad sensory level before and after the surgery and the duration of the surgery. The duration of surgery was defined as the time when surgical preparation began until the surgery finished. Blood pressure (BP), pulse, nausea/vomiting $(\mathrm{N} / \mathrm{V})$ were recorded at three different times: before and after transfer to the stretcher and upon arrival in Recovery Room. Need for intervention to sustain $\mathrm{BP}$ was also recorded during the transport period. Hypotension, defined as $>20 \%$ decrease of baseline systolic BP, was treated with ephedrine iv. Baseline measurements were the recordings taken at the end of the Cesarean section prior to transfer to the stretcher.

Differences in the frequency of effects between the two groups using a test for two proportions and differences yielding $P$-values $<0.05$ were considered statistically significant.

\section{Results}

Satisfactory spinal anesthesia was achieved in all patients. None required general anesthesia or complained of difficulty with breathing, swallowing or phonation.

Demographic data of the 199 patients studied are presented in Table I. Ninety-three percent of patients were blocked within the $T_{4}-C_{8}$ range before surgery and $86 \%$ in the same range after surgery. More patients had sensory levels higher than $\mathrm{C}_{8}$ at the end of the procedure than before (Table II). Table III shows the changes in dermatome level at the end of surgery, compared with the initial dermatome. Block levels at the end of surgery were within one dermatome of the original in $74 \%$, higher than this range in $17 \%$ and lower in $8.5 \%$ (Figure).

Mean BP and pulse during and after transport to Recovery Room were similar in both groups. Pulse rates varied widely at the end of surgery but there was no change produced by transport (Table IV). There was a $3 \%$ incidence of hypotension in both groups after transferring the patients onto the stretcher. The incidence of hypotension on arrival in Recovery Room was greater, but similar in both groups; group $A=10 \%$ and group $B=9 \%$. Both groups required ephedrine to sustain $B P$ (Group $A=13 \%$ and group $B=7 \%$ ), but the difference was not statistically significant $(P=0.2)$. There was also no significant difference in the incidence of nausea and vomiting between Group $A$ and B (Table V).

\section{Discussion}

Hypotension is a common complication of spinal anesthesia and is the consequence of decreased cardiac output and reduced total peripheral resistance induced by sympathetic blockade. The incidence during Cesarean section has been reported to be between 30 - 
TABLE I Demographic characteristics: mean (range)

\begin{tabular}{lll}
\hline & Group A & Group B \\
\hline Patients & 111 & 88 \\
Height $(\mathrm{cm})$ & $162(142-178)$ & $162(142-180)$ \\
Weight $(\mathrm{kg})$ & $75(49-137)$ & $77(54-125)$ \\
\% in Labor & 23 & 24 \\
\% Emergencies & 23 & 24 \\
Duration of Surgery (min) & $74(30-150)$ & $77(27-138)$ \\
\hline
\end{tabular}

TABLE II Number (percentage) of patients at each spinal dermatome level beforc and after Cesarean section

\begin{tabular}{lll}
\hline Dermatome Level & $\begin{array}{l}\text { Before } \\
n(\%)\end{array}$ & $\begin{array}{l}\text { After } \\
n(\%)\end{array}$ \\
\hline $\mathrm{C}_{3}$ & $0(0)$ & $1(0.5)$ \\
$\mathrm{C}_{4}$ & $2(1)$ & $2(1)$ \\
$\mathrm{C}_{5}$ & $1(0.5)$ & $5(2.5)$ \\
$\mathrm{C} 6$ & $3(1.5)$ & $3(1.5)$ \\
$\mathrm{C}_{7}$ & $4(2)$ & $6(3)$ \\
$\mathrm{C}_{8}$ & $17(8.6)$ & $20(10.1)$ \\
$\mathrm{T}_{1}$ & $43(21.6)$ & $60(30.2)$ \\
$\mathrm{T}_{2}$ & $69(34.7)$ & $54(27.1)$ \\
$\mathrm{T}_{3}$ & $14(7)$ & $16(8)$ \\
$\mathrm{T}_{4}$ & $42(21.1)$ & $22(11.1)$ \\
$\mathrm{T}_{5}$ & $3(1.5)$ & $6(3)$ \\
$\mathrm{T}_{6}$ & $1(0.5)$ & $4(2)$ \\
\hline
\end{tabular}

TABLE III Changes in dermatome level at the end of cesarean section in each patient as compared with the initial level $(+=$ increase of block cephalad; - - decrease of block caudal)

\begin{tabular}{cc}
\hline Number of dermatomes & Nusmber of patients (percentage) \\
\hline+7 & $1(0.5)$ \\
+6 & $2(1)$ \\
+5 & $4(2)$ \\
+4 & $4(2)$ \\
+3 & $13(6.5)$ \\
+2 & $11(5.5)$ \\
+1 & $21(10.6)$ \\
0 & $105(52.8)$ \\
-1 & $21(10.6)$ \\
-2 & $11(5.5)$ \\
-3 & $3(1.5)$ \\
-4 & $3(1.5)$ \\
\hline
\end{tabular}

$60 \%{ }^{3}$ Hypotension may be caused by postural fluid shifts during transfer from the operating table. ${ }^{4,5}$ The incidence of hypotension during post Cesarean transport has not been reported.

After Cesarean section under regional anesthesia is completed, women prefer a moderate degree of head elevation rather than remaining supine. Breathing is more comfortable in this position and it is easier to hold the baby, breast feed and converse with family members.

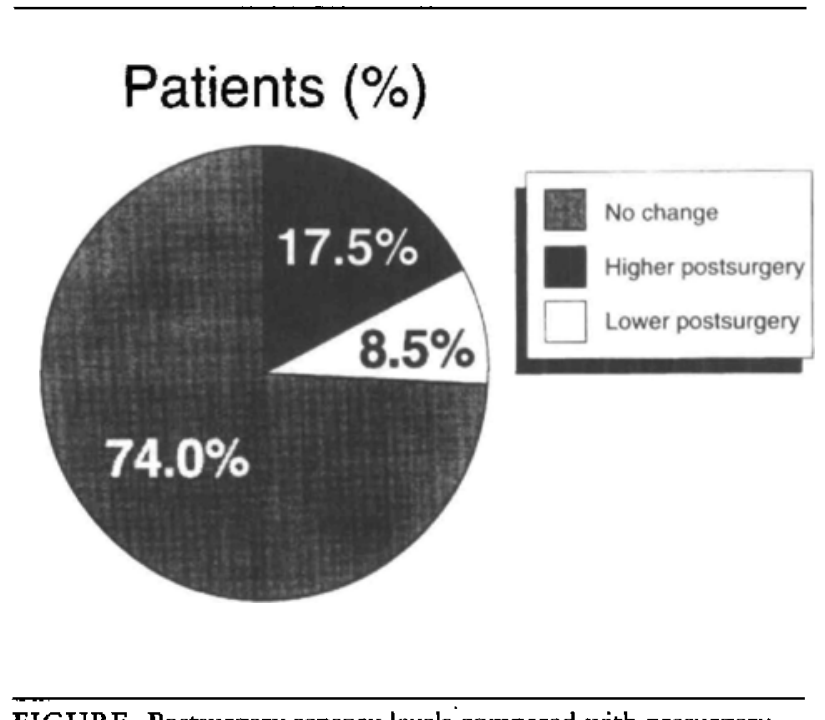

FIGURE Postsurgery sensory levels compared with presurgery (presurgery sensory level defined as measured level \pm one dermatome)

In a study reported in 1950 , tilting the table into reverse Trendelenburg during spinal anesthesia produced hypotension and even fainting. ${ }^{6}$ Little information is available about the effect on blood pressure and pulse when the upper trunk is flexed during spinal anesthesia. In this study, we noted no difference in the incidence of severe hypotension during the transport period between the supine and head-up groups. The cardiovascular effects of tilting only the upper trunk may be less pronounced than whole body tilt in the reverse Trendelenburg position. A recent study of the recovery period after spinal anesthesia in non-obstetric patients showed a decreased incidence of bradycardia in the hammock position (legs and trunk both elevated $30^{\circ}$ ) compared with the supine and Trendelenburg positions. ${ }^{\text {? }}$

Our study showed that $95 \%$ of patients had sensory levels of $T_{4}$ and higher at the end of surgery. In $17.5 \%$ of patients the block was two or more dermatomes higher than at the start. In a few patients the block after surgery extended to $\mathrm{C}_{5}$ and higher. This is of particular concern as the phrenic nerve root is $\mathrm{C}_{3-5}$. All patients had extensive sympathetic block at the time of transfer and, in many, the cardiac accelerator nerves $\left(T_{1-4}\right)$ must have been affected. This leads to relative bradycardia at a time when postural changes cause sudden fluid shifts. A transient decrease in blood pressure may be observed at this time. The transfer period remains one of the least monitored periods during the surveillance of the surgical patient. While most anesthesiologists record the level of block attained prior to Cesarean section, few record levels at a later time. Perhaps it is assumed that the maximum 
TABLE IV BP and pulse during and after transport to Recovery Room: mean (range)

\begin{tabular}{|c|c|c|}
\hline & $\begin{array}{l}\text { Group A } \\
\text { Head up }\end{array}$ & $\begin{array}{l}\text { Group B } \\
\text { Supine }\end{array}$ \\
\hline \multicolumn{3}{|c|}{ Before transfer to the stretcher } \\
\hline $\mathrm{BP}(\mathrm{mm} \mathrm{Hg})$ & $118(95-157)$ & $115(87-151)$ \\
\hline Pulse (bpm) & $85(62-115)$ & $86(51-123)$ \\
\hline \multicolumn{3}{|c|}{ Following transfer to the stretcher } \\
\hline Interval (min) & $7(1-16)$ & $8(2-15)$ \\
\hline $\mathrm{BP}(\mathrm{mm} \mathrm{Hg})$ & $119(91-150)$ & $113(85-152)$ \\
\hline Pulse (bpm) & $85(58-113)$ & $84(53-120)$ \\
\hline \multicolumn{3}{|c|}{ Arrival in Recovery Room (relative to before transfer to the stretcher) } \\
\hline Interval (min) & $14(5-25)$ & $13(7-25)$ \\
\hline $\mathrm{BP}(\mathrm{mm} \mathrm{Hg})$ & $110(81-152)$ & $110(81-151)$ \\
\hline Pulse (bpm) & $85(55-115)$ & $84(57-116)$ \\
\hline
\end{tabular}

TABLE V Incidence of hypotension, nausea/vomiting and intervention during and after transport to Recovery Room: percentage (n)

\begin{tabular}{|c|c|c|}
\hline & $\begin{array}{l}\text { Group A } \\
\text { Head up }\end{array}$ & $\begin{array}{l}\text { Group B } \\
\text { Supine }\end{array}$ \\
\hline \multicolumn{3}{|l|}{ Following transfer to stretcher } \\
\hline $\begin{array}{l}\text { hypotension } \\
\text { nausea/vomiting* }\end{array}$ & $\begin{array}{l}2 \%(2) \\
6 \%(7)\end{array}$ & $\begin{array}{l}5 \%(4) \\
2 \%(2)\end{array}$ \\
\hline $\begin{array}{l}\text { nausea/vomitung } \\
\text { intervention (ephedrine) }\end{array}$ & $5 \%(6)$ & $2 \%(2)$ \\
\hline \multicolumn{3}{|c|}{ On arrival at recovery room (velative to before transfer) } \\
\hline hypotension & $10 \%(11)$ & $9 \%(8)$ \\
\hline nausea/vomiting & $8 \%(9)$ & $5 \%(5)$ \\
\hline intervention (ephedrine) & $13 \%(14)$ & $7 \%(6)$ \\
\hline
\end{tabular}

* excluding patients with $\mathrm{N} / \mathrm{V}$ at end of surgery prior to transfer $\dagger$ excluding patients receiving ephedrine immediately prior to transfer

level is reached before the procedure ends and regression has already started at the end of surgery.

Most anesthesiologists agree that a dense block to at least $\mathrm{T}_{4}$ is needed for Cesarean section in order to avoid visceral pain. Hyperbaric bupivacaine, 12-15 $\mathrm{mg}$, has gained wide popularity due to the very dense block it produces. It is often also combined with morphine for prolonged and reliable postoperative analgesia.

De Simone $e t$ al. compared the maximum number of segments blocked for Cesarean section using $12 \mathrm{mg}$ or $15 \mathrm{mg}$ hyperbaric bupivacaine. ${ }^{8}$ More blocked segments were noted with $15 \mathrm{mg}(24.8+3.7)$ than with $12 \mathrm{mg}(22.6+1.4)$. There was also quicker regression to $T_{10}$ and a greater need for intravenous supplements with the $12 \mathrm{mg}$ dose. Three of their patients receiving $15 \mathrm{mg}$ developed $\mathrm{C}_{1} / \mathrm{C}_{2}$ blocks which lasted $15-20$ min. Our results confirm the work of De Simone et al. with regard to high thoracic and cervical sensory spread prior to Cesarean section. However, they did not comment on the levels of block at the end of the surgery. We found high cervical spread in a few patients which had not regressed at the end of surgery but we made no effort to distinguish between the effect of various bupivacaine doses within the range used.

In term parturients $\mathrm{T}_{4}$ block is usually achieved within 10 min of subarachnoid injection of hyperbaric bupivacaine. The maximal cephalad spread has been noted to be attained within $20 \mathrm{~min}$ by De Simone et $a l^{8}{ }^{8}$ or $10-12$ min by Norris. ${ }^{9}$ Norris also commented that the maximal level was stable for at least $45 \mathrm{~min}$ after it was attained. Despite these data, some evidence suggests that the block may progress higher during surgery. Mulroy suggests that further spread may occur as long as $30 \mathrm{~min}$ after injection. ${ }^{4}$ Another indicator that the level of spinal block may be rising is the occurrence of bradycardia as a result of high sympathetic block. Carpenter reported that bradycardia can occur 30-60 min after spinal injection. ${ }^{10}$ In an ASA closed claims study, Caplan reported cardiac arrests $36 \pm 18 \mathrm{~min}$ following induction of spinal anesthesia. ${ }^{11}$ From the results of our study, we postulate that the anesthesia levels may have been higher at the time of these arrests than at the start of surgery.

At levels above $T_{4}$, preganglionic sympathetic fibers to the heart $\left(\mathrm{T}_{1.4}\right)$ are affected and may cause bradycardia due to overriding parasympathetic activity. ${ }^{12}$ Inconsistent data have been published of the correlation between sensory and sympathetic block levels, but most demonstrate attenuation of sympathetic function with high thoracic anesthesia. ${ }^{13,14}$ Initial reports suggested that sympathetic block extended to dermatomes above the level of sensory blockade and these were confirmed using different local anesthetics. ${ }^{15}$ Chamberlain and Chamberlain used thermographic imaging and found that partial sympathetic block extended for six or more segments above the level of sensory analgesia. ${ }^{16}$

In conclusion, prior to Cesarean section under spinal anesthesia with hyperbaric bupivacaine, 12-15 $\mathrm{mg}$, and morphine, the spinal block is usually at $\mathrm{T}_{4}$ and higher. The sensory block level may continue to rise during surgery and be higher at the end than at the beginning in many patients. At the time of transfer to the stretcher, the extremely vasodilated patient (with possible predominant vagal tone) is subjected to marked postural stress and fluid shifts. At this time monitoring is usually minimal or non existent. Transfer in some institutions may involve a protracted period in corridors and elevators. After arrival in Recovery Room, the patient is as extensively blocked as she was in the Operating Room while under the continuous care of an anesthesiologist. She 
will now not receive the same degree of attention, and it may take considerable time for the block to regress. The transfer period deserves closer scrutiny and monitoring, as this is a time when disasters can occur. ${ }^{1}$ Raising the head for the comfort of the mother during transport did not increase the risk of hypotension. We recommend routine monitoring of blood pressure and pulse after transfer to the stretcher and recording the sensory level of block at the end of Cesarean Section. Evidently a high block persists even after surgery has finished.

\section{References}

1 Scull T7, Carli F. Cardiac arrest after Caesarean section under subarachnoid block. Br J Anaesth 1996; 77 :

274-6.

2 Gambling DR. Cardiac arrest after Caesarean section under subarachnoid block. (Letter) Br J Anaesth 1997; 78: 109-10.

3 Shnider SM, Levinson G. Anesthesia for Cesarean section. In: Shnider SM, Levinson G (Eds.). Anesthesia for Obstetrics, 3rd ed. Baltimore: Williams \& Wilkins, 1993: 211-45.

4 Mulroy MF. Regional Anesthesia, An Illustrated Procedural Guide, 2nd ed. Boston: Little, Brown \& Company, 1996: 60-95.

5 Bridenbaugh PO, Greene NM. Spinal (subarachnoid) neural blockade. In: Cousins MJ, Bridenbaugh PO (Eds.). Neural Blockade in Clinical Anesthesia and Management of Pain, 3rd ed. Philadelphia: Lippincott, 1998: 233.

6 Pugh LGC, Wyndbam CL. The circulatory effects of high spinal anaesthesia in the hypertensive and control subjects. Clin Sci 1950; 9: 189-203.

7 Ponbold H, Vicenzi MN. Incidence of bradycardia during recovery from spinal anaesthesia: influence of patient position. Br J Anaesth 1998; 81: 723-26.

8 De Simone CA, Leighton BL, Norris MC. Spinal anesthesia for Cesarean delivery. A comparison of two doses of hyperbaric bupivacaine. Reg Anesth 1995; 20: 90-4.

9 Norris $M C$. Height, weight and the spread of subarachnoid hyperbaric bupivacaine in the term parturient. Anesth Analg 1988; 67: 555-8.

10 Carpenter RL, Caplan RA, Brown DL, Stephenson C, $W u R$. Incidence and risk factors for side effects of spinal anesthesia. Anesthesiology 1992; 76: 906-16.

11 Caplan RA, Ward RJ, Posner K, Cheney FW. Unexpected cardiac arrest during spinal anesthesia: A closed claims analysis of predisposing factors. Anesthesiology 1988; 68: 5-11.

12 Greene NM, Brull SJ. Physiology of Spinal Anesthesia, 4th ed. Baltimore: Williams \& Wilkins, 1993: 14-21.

13 Stevens RA, Frey K, Liu SS, et al. Sympathetic block during spinal anesthesia in volunteers using lidocaine, tetracaine, and bupivacaine. Reg Anesth 1997; 22: 325-31.

14 Bengtsson $M$, Löfström JB, Malmqvist $L-A$. Skin conductance responses during spinal analgesia. Acta Anaesthesiol Scand 1985; 29: 67-71.

15 Brull SJ, Greene NM. Time-courses of zones of differencial sensory blockade during spinal anesthesia with hyperbaric tetracaine or bupivacaine. Anesth Analg 1989; 69: 342-7.

16 Chamberlain DP, Chamberlain BDL. Changes in the skin temperature of the trunk and their relationship to sympathetic blockade during spinal anesthesia. Anesthesiology 1986; 65: 139-43. 